\title{
Fine and Applied Arts of King Narai Festival and the Perception of Lopburism
}

\author{
Haruetai Naimoke ${ }^{1}$, Pattamawadee Chansuwan ${ }^{1} \&$ Ourarom Chantamala ${ }^{1}$ \\ ${ }^{1}$ Faculty of Fine and Applied Arts, Mahasarakham University, Khamriang Sub-District, Kantarawichai District, \\ Maha Sarakham Province, Thailand \\ Correspondence: Haruetai Naimoke, 557/6, Moo 10, Khok Kruat Sub-District, Mueang District, Nakhon \\ Ratchasima Province, Thailand. E-mail: koo_kai2517@hotmail.com
}

\author{
Received: September 1, 2013 Accepted: September 9, 2013 Online Published: November 29, 2013 \\ doi:10.5539/ass.v9n17p238 URL: http://dx.doi.org/10.5539/ass.v9n17p238
}

\begin{abstract}
The King Narai Festival of Lopburi Province is a long-standing tradition that has enabled the development of the provincial identity. This research had two primary aims: to study the background and development of the King Narai Festival in Lopburi Province and to analytically study, select and present the concept of Lopburism in the fine arts activities of the light and sound shows of the King Narai Festival. The research found that the event has been held twenty-six times in a thirty-three year period since 1979. The analysis of the development of the King Narai Festival in Lopburi Province can be divided into four time periods: introduction, improvement, identity creation and value increase. The activities during the festival are able to create unity and an identity for the event and can reveal and provide deep knowledge of the essence of Lopburi people. This essence, Lopburism, can be summarized as follows: a) belief in, respect for, faith in and worship of King Narai the Great; b) the lifestyle and existence of Lopburi people during the era of King Narai the Great; c) important events during the era of King Narai the Great, including the people with important roles during the time. The explanations given in this paper show the selection process and production of activities during the King Narai Festival for presenting the identity of Lopburism.
\end{abstract}

Keywords: Lopburism, King Narai the Great, festival, fine and applied arts, identity

\section{Introduction}

Lopburi is a city with a long history that has passed through many stages of progression. It was the second most important city during the reign of King Narai, complete with modern academia and was the most advanced city of the time. Nowadays, Lopburi is known throughout the world for its variety in history, beautiful ancient ruins and interesting legends. It is a province in the Central region of Thailand on the left banks of the Lopburi River, covering 6,198.558 km² (Office of Planning and Projects, 1987, p. 30). Lopburi is a city with a variety of continuous history for over three thousand years. It is an ancient territory with a long history from prehistory to the modern day. In the past, during the twelfth Buddhist century, Lopburi was known as Lawo or Lavapura (Lawabura). It was an important city on the East of the Chao Phraya River because the surrounding environment was suitable and it could be connected by river and over land. This caused Lopburi to become an important location for foreign trade and export, as well as a Buddhist center. Particularly important was trade with the Kingdom of Cambodia, which was an important center of power at the time. This allowed the Cambodian art and culture to enter Lopburi and influence different areas of development, thus transforming Lopburi into a more advanced city than those surrounding it along the banks of the Chao Phraya River.

At the time of King Uthong, the first ruler of the Ayutthaya Kingdom, Lopburi was a Loog-Luang city, which meant that King Uthong allowed his first son, Ramesuan to rule. In 1350, Ramesuan began creating a fortress, mote bank and secure city wall. When King Uthong passed away in 1369, Ramesuan was deposed as King of Ayutthaya by Borommaracha I but retained rule of Lopburi until 1388. When Borommaracha I passed away, Ramesuan was once again named as King of Ayutthaya, causing Lopburi to lose its importance. This remained until the rule of King Narai the Great (1656-1688), when Lopburi underwent intensive maintenance to stave off the threat of Dutch trade. This made King Narai realize that Ayutthaya was not immune to enemy siege and war and so Lopburi was named as the second city of the kingdom due to its strategic features. 


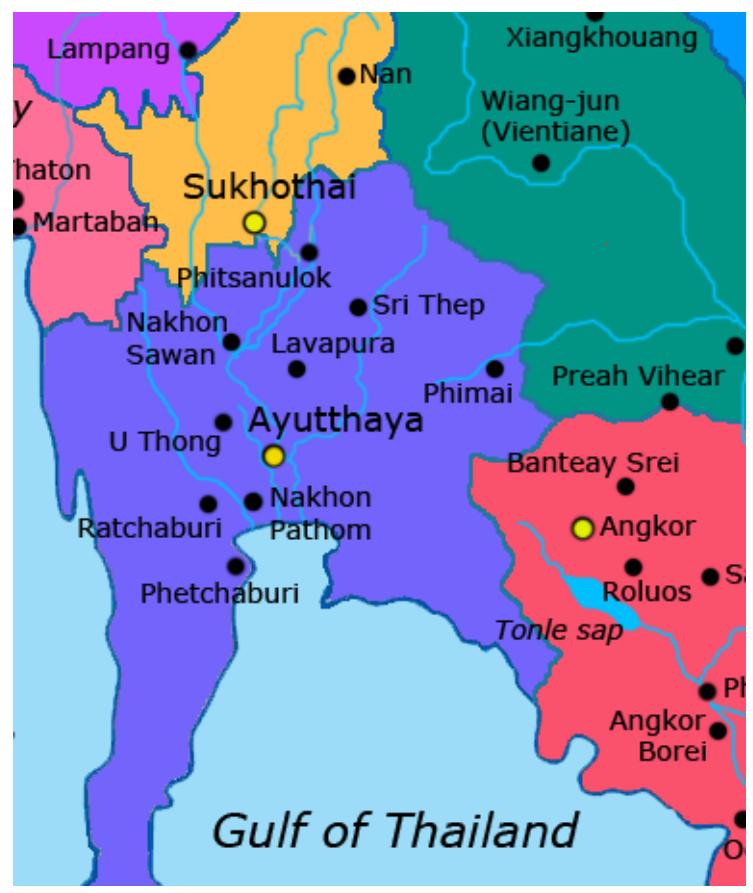

Figure 1. A map of the Ayutthaya Kingdom, showing Lavapura (Lopburi)

For this remodeling of Lopburi by King Narai the Great, the help of French and Italian nationals was enlisted and a royal palace and fortress were built to strengthen and protect the city. After this, King Narai the Great spent most of his time at Lopburi. After the death of King Narai the Great, the importance of Lopburi was reduced. King Phetracha relocated the entire government to Ayutthaya. No future king would return the government to Lopburi, until King Mongkut (Rama IV) of the Rattanakosin dynasty in 1863, who led a renovation of the city by repairing the city walls and restoring the fortress and the palace gates. The new throne hall complex of Phiman Mongkut Pavilion was also created. Lopburi thus became an important city once again. Afterwards, Lopburi was further preserved during the government of Field Marshal Plaek Phibunsongkhram, who established a military city to the East of the railway line, while the old city lay to the West. Lopburi was thus a strategically important city.

Lopburi Province holds an important annual festival every February called the King Narai Festival, which involves the participation of all areas of government and the private sector. This can be seen in the creation of event identity, notably the wearing of traditional Thai dress by all participants and audience members, which stemmed from the basic principle and selling point of the event as a time when 'all Lopburi people come together to wear traditional Thai dress'. Aside from promoting and showcasing the cooperation of the people, government and private sector in Lopburi, the traditional Thai dress policy also draws the attention and interest of domestic and foreign tourists. There is a show that incorporates acting, lighting, sound and imagery on the subject of King Narai's Kingdom, which is the principal activity for passing on the legends of Lopburi province during the time of King Narai's Kingdom. The show aims to present a recollection of the royal grace of King Narai, the person who caused Lopburi to progress and advance.

Performances with light and sound are new forms of cultural performances that came about through the mixture of science and arts from many departments, including classical dance, drama, lighting techniques, color and sound. They are performances that stand out in their use of light, sound, color and music to present historical stories in actual historical locations. With this in mind, the performances must understand the situations and areas that they are presenting. They use descriptive sound to explain the stories, music and percussion to create emotion and make the piece more beautiful and poetic, and lights and colors to create atmosphere and help the audience to imagine the story. These elements allow the audience to think and feel as if they were in the story. This is a way to mix reality and imagination. Archaeological sites or important historical sites across Thailand become important places for light and sound performances at different times in order to retell the stories of history mixed with performance techniques and new technology. This, aside from providing knowledge of 
historical stories to the audience, also reveals lifestyle, culture, existence and inheritance through performance.

The information discussed here, shows that performance art combining the science and art of fine arts, together with techniques and new technologies in light, sound and color in the form of light and sound performances help retell the stories or present the pictures of events in the past, as well as the lifestyle or culture of the community. These are held in at ancient monuments or important historical places. The light and sound shows at the festival of King Narai of Lopburi Province are especially important, as they have been essential components of the show since 2007. There is another important show at the festival, called the performance of imaginative history for which the municipality of Khao Sam Yot is responsible. This means that the King Narai Palace area has held two major light and sound shows continuously. In thirty-three years, since 1979, the King Narai Festival has been held twenty-six times and is popular with all people who have attended, including foreign visitors and tourists. This can be seen in the increased duration of the festival over time from two of three days to five and subsequently seven days since 2010 , as well as the acceptance among the tourist community. The excellent levels of participation in adhering to the traditional Thai dress customs across the province are important in influencing tourists to visit Lopburi Province during the festival. The stories of the King Narai era are used as the fundamental concepts of the event by using fine arts activities to pass on and present information of Lopburi Province during this era to the modern generations. The researchers realized the value of the festival in terms of fine arts that has a benefit in communicating the valuable stories of the past. It is also important for the inheritance of knowledge, beliefs, local wisdom and the cultural identity of Lopburi Province. Therefore, there should be investigation of the background and development of the King Narai Festival in Lopburi Province, including the fine arts processes used to present Lopburism during the festival. This investigation would ensure the continuity and increase the potential of the King Narai Festival by using fine arts as the media for inheritance of cultural heritage and support of historical and cultural tourism in Lopburi Province for the future.

\section{Research Aims}

The research aimed to study the background and development of the King Narai Festival in Lopburi Province and to analytically study, select and present the concept of Lopburism in the fine arts activities of the light and sound shows of the King Narai Festival.

\section{Research Methodology}

This is a qualitative study using a variety of suitable research methods for the topic, such as ethnographic research to study the historical and cultural theories related to the analytical study of Lopburism; phenomenology to study symbolic interaction theory; analytical study of knowledge and expression of Lopburi residents towards the organizations of King Narai, including the concept, designs and implementation of activities during the King Narai Festival; theoretical research from the data collected to create and select theories for the inheritance of culture and symbolic interaction theory in order to analyze interpretation, selection and implementation of the presentation of Lopburism at the King Narai Festival; theories of aesthetics, fine art concepts of inheritance and local historical concepts in the analysis of using fine art during light and sound performances for the presentation of Lopburism. This research also included the study of historical data and development of Lopburi, as well as the royal biography and royal grace of King Narai in creating Lopburi as an advanced city with modern academia and transforming it into an important part of the Ayutthaya Kingdom. This transformation had an effect on beliefs, respect of royalty, respect of Lopburi people towards King Narai from the past to the present and the history of light and sound shows in Thailand, including the important factors in organizing light and sound productions during the history of the King Narai Festival. During this research, the researchers also studied related theories, including local historical concepts, concepts of identity, symbolic interaction theory, aesthetics theory, reproduction theory for the inheritance of culture and customs, and theories of historical culture. This was to analytically study the King Narai Festival to identify benefits and value for the supplementation and lasting development of fine arts. The research methodology followed the methodological steps outlined by Supang Jantawanit in the book Qualitative Research (1999). Additionally, the research was designed to support historical tourism in Lopburi Province, according to the provincial tourism strategies based on the foundations of cultural identity and local wisdom.

\subsection{Population and Sample}

The population selected by the researchers for this study totaled ninety-six individuals related to the organization of the King Narai Festival in Lopburi Province. They were divided into three groups, as follows:

\subsubsection{Key Informants}

Key informants included sponsors of the festival and festival directors. These included the provincial governor, 
heads of government departments that had been assigned responsibility in the organization of the festival or were involved in the light and sound performance at the festival. There were six key informants.

\subsubsection{Casual Informants}

Casual informants included twenty-five individuals involved with or responsible for the production and implementation of events and activities at the festival, including the conception and organization of the light and sound shows in the inner area of King Narai Palace. Also included were fifteen individuals involved with or responsible for the production and implementation of events and activities at the festival, including the conception and organization of the light and sound shows in the central area of King Narai Palace.

\subsubsection{General Informants}

General informants included visitors to the King Narai festival. These were separated into two subgroups: fifteen people who had visited the festival in both 2011 and 2012 and thirty-five people who visited the festival in 2012 only.

\subsection{Research Tools}

This research used three primary tools for data collection. A questionnaire was used to survey general conditions, opinions of the festival, impression of the knowledge, benefits and drawbacks received from visiting the festival. The questionnaire was given to informants within and surrounding the research area. Structured and unstructured interviews were used to garner information from people related to the organization of the King Narai Festival in Lopburi Province. The interviews were conducted in order to determine the history of the festival, the format of activities within the festival, the concepts of the festival organization, selection and presentation of Lopburism and factors that support the identity of Lopburism and its transmission to visitors of the King Narai Festival in Lopburi Province. Participant and non-participant observations were recorded to assess the behavior of people related to the festival organization, people who came to view the shows and people who came to participate in the activities. The records concerned the satisfaction with the shows and feelings regarding the festival.

\subsection{Data Analysis}

The researchers checked the results throughout the data collection period. Upon completion of data collection, the researchers collected all data from document and field study and performed a typological analysis. This involved separation of data into typologies and checking whether the data was complete and adequate or insufficient. The data was then verified using a methodological triangulation method to determine if it was correct. If there were any anomalies or absences, the researchers returned to the field to collect further data.

The researchers validated all data in the field each time, according to the research questions and whether the meanings met the research requirements and corresponded to the research context, the surrounding environment and existing research. Triangulation was conducted in accordance with a qualitative research method in order to determine whether data meanings were accurate and believable. These results were then taken to a focus group discussion with all informant groups. Data was validated according to quantity, location (data triangulation), source, theory, method (methodological triangulation) and analysis category, as recommended by Supang Jantawanit (1999, p. 23).

Data found in documents and data collected by research tools in the field were taken for typological analysis according to three steps: organization of documents into analysis groups, analysis of documents and analysis of data from survey, observation and interview. The researchers then conducted a descriptive analysis according to the research aims.

\section{Results}

The results of this study are arranged according to the aims of the research, as follows:

\subsection{The Background and Development of the King Narai Festival in Lopburi Province}

The organization of the King Narai Festival came from the concepts of the conservation association of ancient monuments and surrounding environment in Lopburi Province established by Chawawat Sudrapa, the Provincial Governor of Lopburi at the time. The original objectives of the event were to develop Lopburi as a tourist city and to honor His Majesty King Narai for the progression of Lopburi. The original name for the event was the 'Recollection of King Narai' and it was to be held from the $21^{\text {st }}$ to the $22^{\text {nd }}$ of October, 1978. However, due to flooding in the province, the event was moved to $17^{\text {th }}$ to $18^{\text {th }}$ of February, 1979. The name of the event was changed to the King Narai Festival and it was held in February each year because it was the month of King Narai's birth. Activities in the festival are reproductions of past events in the area of King Narai's Palace. Aside from this, important things in the area are used to reveal the legends of the past and the identity of Lopburi 
Province. These are used as the founding concepts of the festival and include demonstrative performances of past lifestyle and sale of local indigenous products that are part of the Lopburi provincial identity. One further part of the festival is the wearing of traditional clothing that is supported by all departments of the government and private sectors in Lopburi Province, including the people attending the specific heritage costume activity and the people attending all areas of the festival. There are light and sound activities that add importance to the history of King Narai's era in a way that foreign visitors can relate to. This is a way to tell historic stories through the medium of acting, including the techniques of light and sound in important ancient historic monuments.

Activities organized during the King Narai Festival aim to pass on knowledge regarding the divine grace of King Narai the Great to participants. The activities also aim to impressively reveal the images of the past during the era of King Narai at King Narai Palace, which was established as a residence for King Narai in Lopburi. The activities may be categorized into five groups: honorary activities, academic activities, activities to reveal lifestyle, entertainment activities and fund-raising activities.

Data concerning the development of festival organization from 1979 to 2012 revealed that the event has been held twenty-six times in the thirty-three year period. The analysis of the development of the King Narai Festival in Lopburi Province can be divided into four time periods: introduction, improvement, identity creation and value increase. The activities during the festival are able to create unity and an identity for the event and can reveal and provide deep knowledge of the essence of Lopburi people. The activities can provide influence and interest for the tourists and audience, which has caused the King Narai Festival to continue from its inception to the present day.

\subsection{Process for Selection and Presentation of the Concept of Lopburism in the Fine Arts Activities of the Light and Sound Shows of the King Narai Festival}

The process for selection and presentation of activities at the event is according to the objectives of the festival, presentation and specification of event concepts to present the idea of Lopburism for inheritance through the various activities of the festival. This shows people the meaning and feeling of Lopburism, which can be summarized as follows: a) belief in, respect for, faith in and worship of King Narai the Great; b) the lifestyle and existence of Lopburi people during the era of King Narai the Great; c) important events during the era of King Narai the Great, including the people with important roles during the time. The event organizers allow the festival participants to receive knowledge through the many activities of the festival by providing ideas of belief in, respect for, faith in and worship of King Narai the Great in the form of activities before the start of the festival. These activities include the honor ceremony, ceremony to ask for permission to hold the ceremony and the worship ceremony. These ceremonies use fine arts performances to connect to the audience and convey their message, including Khon style performance, worship dancing and krabi krabong pole fighting on the birthday of King Narai the Great, which coincides with the first day of the festival. These activities will showcase the lifestyle and existence of Lopburi people during the era of King Narai and combine with a traditional market fair, the wearing of traditional Thai costume, the Narai Palace Evening Ball, the reproduction of lifestyle in the festival area and Thai lifestyle activities. These are prominent activities of the festival and allow the visitors to participate and be influenced. The activities draw continual tourism and thus help generate income for the community economy. There are also exhibitions to showcase and pass on the stories, legends, important events during the era of King Narai the Great and people with important roles during the time so that the visitors may gain knowledge in the foundations of Lopburism. Knowledge provided by these exhibitions is supplemented by the light, color and sound shows that present the two areas within King Narai Palace.

The presentation of Lopburism at the King Narai Festival can be concluded in three forms: a) presentation in a variety of activities; b) presentation in the form of real information to stimulate imagination by reenacting important events in the festival area to recreate the feelings and atmosphere of progressive Lopburi during the era of King Narai the Great; c) presentation by participation of Lopburi people in the assignment of responsibility for the festival and creation of activities so that the visitors to the event may participate in turn as though they were from the area. Fine art performances of light, color and sound in the two areas of King Narai Palace are used as media to transmit the important 'substances' that the organizers must pass on. These are: a) the communication of the power of love and unity of Lopburi residents; b) the communication of beliefs, faith, respect and worship of King Narai the Great of Lopburi; c) the communication of knowledge and understanding in historical stories; d) the communication of creative power and inheritance of art culture, in the disciplines of visual arts, classical dance, the art of playing music, literature and architecture; e) the communication of new knowledge and transmission of academic historical knowledge.

The value of fine arts is in the benefit to the inheritance of historical stories and knowledge, belief, local wisdom 
and cultural identity of Lopburi. This is achieved by using fine arts as media to create knowledge transfer and realization of Lopburism through the activities at the festival and the performances of light, color and sound. These are ways to transmit and pass on cultural heritage and support historical and cultural tourism in Lopburi and can be used to increase the potential and ability of the King Narai Festival so that it may continue to exist. By using fine arts, cultural heritage and local wisdom in the creation of added value for the local community, the King Narai Festival may be used as a prototype for the organization of events in other communities in the future.

\section{Discussion}

From the results of the research, the discussion section has been divided according to the original research aims, as follows:

\subsection{The Background and Development of the King Narai Festival in Lopburi Province}

Results regarding the background and the founding concepts of the festival correspond to the research of Thida Saraya, which concerned Local History: The Relationship between the Past and the Present (1985). Saraya presented the concept that humans often create relationships between their past and present, so as to better understand their own background. Each community will thus create its own local history to connect the past and present. Lopburi is no exception and, following the recommendation of the government, constructed a King Narai monument and established the King Narai Festival to worship and celebrate their famous king, his divine grace toward the province and nation and his influence on the reputation of Lopburi so that it may compete with other provinces. In addition, the provincial emblem is a picture of King Narai atop Pra Prang Sam Yod Temple and acts as another memorial to the great King in Lopburi local history. In some social phenomena there is a relationship between the past and present that will enable that phenomenon to continue in the future. In certain circumstances this relationship may create a symbol, custom or ceremony. The King Narai Festival is an activity that links the past and the present so that it has a meaning for people in the community with regards social phenomena that cross dimensions from the past to the present. This is a history that runs adjacent to the past of all groups in all eras and creates a meaning from the past for the present. Equally, the history of this place has a mixed responsibility, causes the integration of responsibility of cultural harmony for people in the local area and creates unity of social and cultural knowledge among the people, which is found in the model of the King Narai Festival.

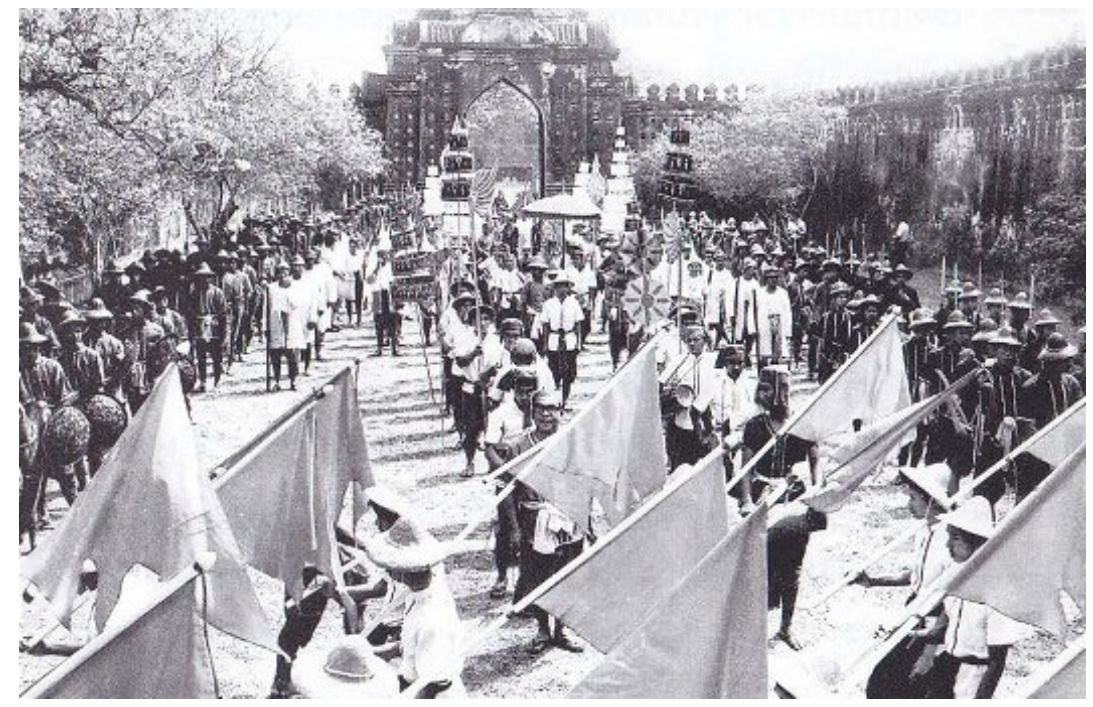

Figure 2. Parade at the $1^{\text {st }}$ King Narai Festival

The analysis of the development of the King Narai Festival in Lopburi Province can be divided into four time periods: introduction, improvement, identity creation and value increase. The first period of introduction began with the first festival in 1979 (including the planning stage in 1978) and finished with the ninth festival in 1993. This was the starting period of the event organization. It was found that this first period was important for defining the format and characteristics of the event by taking the objectives of the first festival to increase income and integrating it with the ancient monuments of Lopburi Province, supporting tourism activities in Lopburi and honoring King Narai the Great. Outlining specifications for the festival caused the organization of activities during the event that were related and linked to presenting the importance of Lopburi Province, 
alongside the important historical events during the era of King Narai the Great. These were the first causes for the creation of the event as a historical festival that collected the past lifestyle and stories of Lopburi during the era of King Narai the Great and presented them in the form of various activities. The improvement stage began with the tenth festival in 1994 and finished with the sixteenth festival in 2001. This period saw the adaptation and development of the festival as an annual event for the entire province and included the participation of all provincial organizations. This allowed for the development and adaptation of the format and increased the variety of activities during the event. This included the increased importance of the light, color and sound shows, the organization of entertaining performances around the King Narai Throne Hall complex, beautiful lighting decoration and a clear plan for the festival. There was also advertising on the television, such as in 2001 when there was a King Narai beauty pageant. In the same year, the committee and those responsible for the traditional Thai dress campaign began to outline a plan for the wearing of Thai dress during the event. This was the stage for defining the planning of the festival and adapting the development of the event organization. The third stage, identity creation, began in 2002 at the $17^{\text {th }}$ festival and lasted until the $22^{\text {nd }}$ festival in 2007 . During this time, the organizers defined a specific identity for the festival, so to make prominent characteristics for easy identification and to attract the interest of visitors and tourists. The specific aspect of identity created was the wearing of traditional Thai dress. The development of costume by the Thai dress campaign council led to its recognition as a symbol of the event from the people of Lopburi Province. The people followed the campaign and participated in wearing traditional Thai dress, following the lead of the provincial governor and his wife. The final stage, value increase, began at the $23^{\text {rd }}$ festival in 2009 and runs until the present day (2012 at the time of research). This was the stage for adding value to the economy and society and is a continuation of stage three in that it revolves around the development of the specific festival identity by increasing the emphasis on traditional Thai dress and extending the festival length from three (and occasionally five) days to seven from 2009 onwards. This has had an effect on the economy and society because there is increased production of modern goods to meet the requirements of the tourists and visitors to the festival who wish to wear traditional Thai dress at the festival. Aside from this, there is greater creativity in the development of products related to the identity of Lopburi that are taken for sale at the festival. There has also been development from each of the previous stages in the history of the festival.

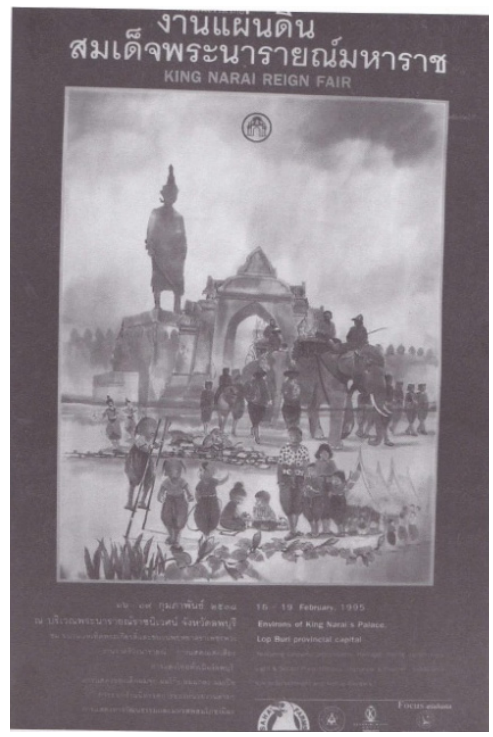

Figure 3. Poster to advertise the King Narai Festival of 1995

These findings correspond to the research of Titisak Wetkama (2010, p. 260), which stated that the most important characteristic of identity was the use of symbols because they express different relationships. Wetkama identified two levels of identity, which were personal identity and social identity, which are used as representations and are important for revealing the path or collective identity. Identity is an important product of society and expresses the relationship between one person and another. Identity derives from the creativity of people and can reveal the feelings of recognition. This is not different from the identity of the King Narai Festival, which has been developed with its own identity. This identity has been communicated and promotes the concept of Lopburism through the presentation of light, color and sound productions and other activities during 
the event.

\subsection{Process for Selection and Presentation of the Concept of Lopburism in the Fine Arts Activities of the Light and Sound Shows of the King Narai Festival}

From the twenty six festivals held to date, the researchers identified a number of important features of Lopburism. The King Narai Festival was held in honor of King Narai the Great and in order to add value to Lopburi Province. The format of the event was a historical festival with reenactments and reproductions of the era of King Narai the Great, which help to present the concept of Lopburism via the use of light, color and sound. The festival corresponds to the symbolic interaction theory of George Herbert Mead and Herbert Blumer (1969). These psychologists theorized upon the relationship between people and society. They emphasized that the actions between people must be intended and expressed through symbolic language. This will stimulate a response that is related to that symbolic language. Humans and society have a mutual relationship. Humans must live in a society and a society cannot exist without humans. They are dependent upon one another and must solve their problems collectively. This causes the creation of social structures and the planning of social regulations.

The researchers used the symbolic interaction theory in the analysis of the King Narai Festival and its relationship with the Lopburi people in creating the identity of Lopburism. Lopburism is thus a behavior shared and expressed by people in the province, which has taken the shape of a custom through participation in the King Narai Festival. The culture that has changed and been adapted as a result of the King Narai Festival is the custom of wearing traditional Thai dress for the duration of the event, as well as activities in honor of the divine grace of King Narai the Great, such as the honor ceremony, ceremony to ask for permission to hold the ceremony and the worship ceremony. This adaptation related to the theory of culture reproduction and culture of selective tradition, as proposed by Raymond Williams (2005). This stated that cultural production and cultural reproduction, whether abstract or concrete, require the same factors or stimuli. Specifically, these factors were raw materials, production tools, delegation system, method, production steps, producers, location, time, production aims and cultural product. It can be seen that the activities used in the King Narai Festival to convey the sense of Loburism are reproductions that have the same factors as listed above. This reproduction may take many forms but the process will be definite and the criteria will be definite in its selection of which aspects of culture to keep and which to discard. Williams named this definite plan, the culture of selective tradition.

From these theories, the researchers completed cultural analysis of the custom of selecting Lopburism present in the King Narai Festival. This included analysis of the naming of the event, the selection of the stories that would be presented, selection of communication and advertising and objectives of presentation (including honoring King Narai the Great). The important criteria in selecting the stories to be communicated are goodness and support of the benefit attained by Lopburi people in creating a progressive province. One further important aim of the festival is the support of tourism. Therefore the selection and creation of activities in the festival require prominent characteristics that are a part of the unique identity of the event and that can attract tourists. This caused the creation of a variety of activities that require participation from the visitors. The explanations given in this paper, show the selection process and production of activities during the King Narai Festival for presenting the identity of Lopburism.

\subsection{Suggestions}

The researchers have outlined two areas for suggestion. In terms of general research, there must be increased study of historical data for use in the planning and management of the King Narai Festival (research and development). This will make the organization and format of the festival more complete. There must also be planning of individual activity management so that each activity is more appropriate for the area provided by the festival organizers. In terms of future research, there are a variety of activities used during the festival that have not yet been deeply studied and investigated. Therefore, there should be examination of these activities in the future, so to increase their value and benefit to academic study.

\section{References}

Blumer, H. (1969). Symbolic Interactionism: Perspective and Method. Englewood Cliffs, NJ: Prentice-Hall.

Deleo, C. A. (1983). Interrelationships Between Job Satisfaction and Leisure Satisfaction for Municipal Recreation Directors in New England. Dissertation Abstracts International, 43(12), 3638A.

Graham, S., Goldblatt, J. J., \& Delpy, L. (1995). The Ultimate Guide to Sport Event Management and Marketing. New York.

Hendee et al. (1984). Wilderness Users in the Pacific Northwest: Their Characteristics, Values and Management Preferences. Washington, D.C.: USDA Forest Service Research Paper, PNW-61. 
Jantawanit, S. (1999). Qualitative Research. Bangkok: Chulalongkorn University Press.

Loring, L. R. (1996, October). Differences in Intentions, Beliefs, and Feelings of Elementary Education Majors Concerning Music Education in the Classroom. Dissertation Abstracts International, 57(4), 1534-A.

Office of Planning and Projects, Tourism Authority of Thailand. (1987). Initial success for the development of tourism in Lopburi, s. $l$.

Saraya, T. (1985). Documents from the second Lopburi history seminar. Seminar documents, s.l.

Wang, J. J. (2006). A study of perceived Key Success Factor among salmon importers and distributors in Shanghai. Master of Science, Norway: University of Tromso.

Wetkama, T. (2010). Cultural theories and concepts. Maha Sarakham: The Research Institute of Northeastern Art and Culture.

Williams, R. (2005). Base and Superstructure in Marxist Cultural Theory. Problems in Materialism and Culture. London: Verso, 1980, Rpt. as Culture and Materialism, London: Verso.

\section{Copyrights}

Copyright for this article is retained by the author(s), with first publication rights granted to the journal.

This is an open-access article distributed under the terms and conditions of the Creative Commons Attribution license (http://creativecommons.org/licenses/by/3.0/). 